\title{
PREDICTORS OF THE STUDENTS' ENGLISH ACHIEVEMENT AT LOWER SECONDARY SCHOOL: CLIL CONTEXT
}

\author{
Sri Rachmajanti ${ }^{a}$ : Mirjam Anugerahwati ${ }^{\text {b }}$ \\ ('sri.rachmajanti.fs@um.ac.id; ${ }^{b}$ mirjam.anugerahwati.fs@um.ac.id) \\ Universitas Negeri Malang, \\ Jl. Semarang No.5, Malang, East Java, Indonesia, 65145
}

\begin{abstract}
English across curriculum has been of world-wide practice, including in Indonesia. Through a blended curriculum (a synergy of national and international frameworks), some schools have put this program into action within the context of CLIL (Content-Language Integrated Learning). This correlational study is intended to find out the correlation between a combination of predictor variables and students' English learning achievement in secondary school in CLIL context. The predictors include the students' interest in ELT, the students' internal and external motivation, the facilities, the exposure to English, and the interactional process between teacher and students at primary school level. The study also investigates to what extent the predictors, in combination as well as individually, contribute to students' English learning achievement in secondary school in CLIL context. Data were collected through questionnaires administered to four secondary schools which implement an international framework. Seventy students were the sample of the present study. The data were analyzed using multiple regression. Results show that the two most significant predictors of the students' English achievement in secondary school are the students' interest and the school facilities.
\end{abstract}

Keywords: Content-Language Integrated Learning, CLIL, lower secondary schools, English learning achievement

DOI: http://dx.doi.org/10.15639/teflinjournal.v30i1/72-87

In order to address the challenges of globalisation, the government of Indonesia through the Ministry of Education and Culture and the Board of Standards of 
National Education have attempted to improve the quality of young generation, "Z generation", through modifying the existing curriculum of secondary schools (called the 2013 Curriculum). The young generation are prospective leaders of the country in the year 2045, the so-called 'the Golden Period'. Through the implementation of the current curriculum they are empowered to be more spiritually, socially, cognitively and skillfully competent for their personal and professional lives.

Unfortunately, education in Indonesia has not shown satisfactory results. In the result of OECD's (Organization for Economic Cooperation and Development) Programme for International Student Assessment in 2009, the literacy competence of the Indonesian lower secondary school students was at 57 th rank out of 65 with the score 396 (compared to OECD score, 493), and in 2013, the score remained 396 against OECD score, 496. It rose only one point in 2015 to 397. In other words, Indonesian students' reading competence is below average.

To overcome this condition, since 2016 the Ministry of Education and Culture has launched a new program called 'Gerakan Literasi Sekolah' or School Literacy Movement nationwide. The literacy program encompasses both Indonesian and English. To accelerate the students' English literacy, some schools have resorted to implementing Content and Language Integrated Learning (CLIL). This integrated learning requires schools to use English as the medium of instruction in the teaching of other subjects, such as Mathematics and Science (Rachmajanti \& McClure, 2011).

CLIL refers to a dual-oriented educational approach. CLIL-lesson is not a language lesson; neither is it a subject lesson delivered in a foreign language. The key characteristics of a CLIL classroom are that language is used to learn and also to communicate, and the language taught is determined by the subject matter (Coyle, Hood \& Marsh, 1999). Coyle et al. (1999) further point out that a CLIL classroom should pay attention to 4Cs: (1) Contents, referring to progression in knowledge, skills and understanding related to specific elements of a defined curriculum; (2) Communication, which refers to using language to learn whilst learning to use language; (3) Cognition, which is developing thinking skills to link concept formation (abstract and concrete), and understanding and language; and (4) Culture, which is exposure to alternative perspectives and shared understandings, which deepen awareness of otherness and self. In CLIL programs, according to Lasagabaster and Sierra (2010), the instruction language is a foreign language which is not exposed to the students' 
local communities (unlike in immersion contexts), and CLIL teachers are nonnative speakers of the language as the medium of instruction. In brief, this approach is an innovative fusion of language and content subjects. All these imply that the process of learning English and other subjects can be mutually interwoven.

Some studies have verified that this way of instruction tends to produce good results. One study by Infante, Benvenuto and Lastrucci (2008), for example, found that although the experienced CLIL teachers in the study came across some problems while carrying out CLIL projects -the lack of available materials, the absence of collaboration in the planning stage, the lack of interest from the teachers of the same class or of the same school, the difficulties in properly integrating content and language as well as creating an authentic and real setting in the classroom - their overall impression of CLIL was positive. Their expertise and motivation could be utilized to overcome the problems. Another study conducted by Fontecha (2014) with Spanish-speaking learners (a CLIL group of 5th graders and a non-CLIL group of 8th graders) examined the connection between receptive vocabulary knowledge and motivation in CLIL and EFL. The study revealed that: (1) both groups were highly motivated, (2) there occured similar distribution patterns of motivation levels in both groups, (3) time of exposure to the foreign language reveals itself as a determining factor for vocabulary size, and (4) some connection between motivation and receptive vocabulary size is only identified in the case of CLIL learners.

In the Indonesian context, a previous study we conducted in 2014 with students of lower and upper classes at the laboratory primary school at Universitas Negeri Malang, Indonesia, found that the students had positive attitude and perceptions regarding the content-based instruction in English implemented in the school, specifically in terms of the provision of varied materials, the variations of teaching-learning activities and media used by the teachers (Rachmajanti \& Anugerahwati, 2014). Approximately $80 \%$ of the students were also sufficiently proficient in English-based Science and Math achieving the band of 5 ( 6 is the highest band). This finding is strengthened by another study which discovered that the lower class students (third graders) of the same primary school who had started learning English through Math and Science earlier (since the first grade) acquired English better. This was seen in their competence in producing declarative, negative and interogative sentences and enriching their vocabulary as they learned the technical terms for Maths and Science besides the high frequency English words (Rachmajanti, Zen \& 
Apriana, 2015). The findings of the studies imply that English instruction through other subjects at early age might construct linguistic foundation for further English learning, and that earlier English instruction at primary schools might result in better English competence at higher level of education. Nevertheless, from an empirical point of view, further studies have to be conducted to investigate the contribution of learning English at primary school to the students' English achievement at lower secondary school in CLIL-based context, which is the main aim of the study.

This study more specifically aims to find out the correlation between a combination of variables or predictors i.e. students' interest in ELT, internal and external motivation, facilities, exposure, and interactional process at the primary school level, to the students' English learning achievement in secondary school in CLIL context. It further seeks to investigate how much the predictors, in combination and individually, contribute to the English learning achievement at the lower secondary school in CLIL context.

\section{METHOD}

A research design that is suitable to address the aims of the study is a correlation design (Price, Jhangiani, \& Chiang, 2015) with regression analysis (Santoso, 2000; Tabachnick \& Fidell, 2001). It is an attempt to reveal how much statistically each of the five predictor variables has a role in the students' learning of English. Schematically, the relationship of the variables is shown in the following Figure 1.

\section{Predictor Variables:}

Criterion Variable:

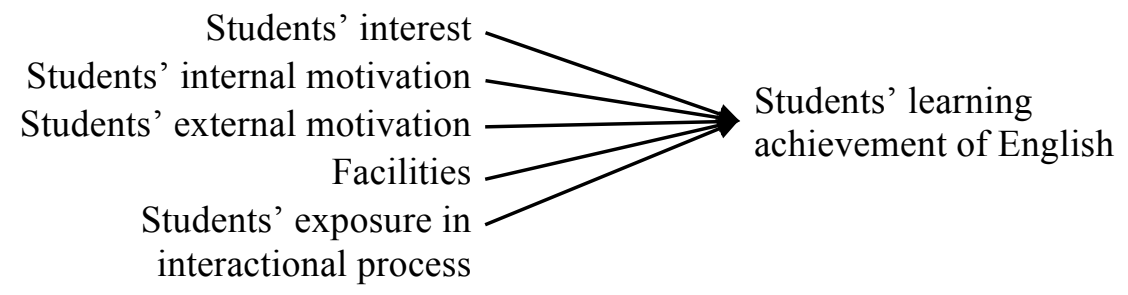

Figure 1. The Relationship of the Variables of the Present Study 
A total of 5 (five) English teachers and 70 (seventy) students from International Class Program (ICP) Grade IX at four lower secondary schools in East Java were taken as the subjects. To ensure confidentiality, pseudonyms are used for the four schools. SMP A, SMP B, SMP C, and SMP D were involved in the present study, constituting the sample. Stakeholders like school principals and ICP coordinators were engaged as well as the source of data. A census of sampling was performed as the sample was actually all the students who were enrolled in the international classes in their respective schools. Therefore, in a way the sampling was a convenience sampling.

To collect the data on the students' interest, students' internal motivation, students' external motivation, facilities, and students' exposure in interactional process, a set of questionnaires was developed. The questionnaires were developed based on the indicators of each of the predictor variables analyzed. The reliability of the questionnaires in the tryout was 0.87 indicating that the questionnaires are considered stable in yielding scores of the students on the predictor variables. Meanwhile, the item-total correlation coefficient of the indicators of each predictor variable fell within a range from 0.4 to 0.5 showing that all the items are precise in measuring the indicators. The data on the students' learning of English were collected from the official document on students' achievement in tests officially conducted to measure their learning English using a CLIL scheme with an international curriculum. The tests measured students' reading and writing.

The data on the predictor variables and the criterion one were scored using interval scale level of measurement prior to data analysis. Then, the data were descriptively analyzed using descriptive analyses to examine the data characteristics in terms of the mean and the standard deviation as well as the minimum and the maximum score for each predictor variable. To assure the right inferential statistic to use, the data were checked against statistical assumption fulfillments. Empirically, if the data fulfilled statistical assumptions of homoscedasticity, linearity, and normality (Hoekstra, Kiers, \& Johnsons, 2012), the parametric inferential statistical analyses could then be used to test the statistical hypotheses raised in the present study. In reverse, if the statistical data assumption test goes against the prerequisite, the statistical hypothesis test used is non-parametric statistics (Hatch \& Lazaraton, 1991) meaning that a statistic is defined to be a function on a sample and there is no dependency on a parameter. 
The present study mainly focuses on these three main aspects: whether the correlation between the predictor variables and the criterion variable in the regression equation is significant; if so, how much is the coefficient of determination of the correlation; finally, what is the beta weight of each of the predictor variables. To answer these, ANOVA was carried out which was run using SPSS version 21.

Data collection instruments were designed and developed based on the mapping of variables, sub variables and descriptors in the blueprint of each instrument. There were three kinds of instruments, i.e., English test for the students, a questionnaire for the students, and an interview guide for the English teachers. All instruments were validated and tried out by ELT experts of the English Department of Universitas Negeri Malang.

The data were collected in three ways; first, the students took a test; second, they responded to a questionnaire after taking the test; and third, the researcher did interviews with the stakeholders (principal and ICP coordinator) and English teachers while visiting the schools. The collected data were then scrutinized and analyzed based on the nature of each type of data. The test scores were statistically analyzed using SPSS, the results of the questionnaire were calculated based on frequency count, and the results of interviews were qualitatively described.

\section{FINDINGS AND DISCUSSION}

There are procedures to be followed prior to the statistical measurement of the relationship of the criterion variable- the students' achievement test (Y)and the five predictor variables- Variable 1 (X1) deals with the students' interest, Variable 2 (X2) with the internal motivation, Variable 3 (X3) with the external motivation, Variable 4 (X4) with the school and home facilities, Variable 5 (X5) with the English exposure in the interactional process. Since this study employs multiple regression, the assumptions of the multiple regression should be fulfilled.

Based on the statistical analysis using Spearman rho, there was evidence that some of the assumptions for multiple regeression (Hatch \& Lazaraton, 1991) were partly fulfilled. As evidence, firstly, the ordinal number (the Likert system 1 to 5) obtained from the questionnaire was converted into the interval data using successive intervals. To do so, the ordinal data of the predictor variables were converted into the interval data to be compatible with the 
interval of the dependent data prior to further statistical analysis. Secondly, the relationship between the predictor variables and the criterion variable was linear implying that the change in the criterion was somehow associated with the predictor variables. Thirdly, however, the data analyzed were not in a normally distributed curve. Since the statistical assumptions of the application of the analysis of multiple regression are not satisfactorily fulfilled, the statistical hypothesis test employed is not parametric statistics allowing us to nominate parameters for evaluation, define the parameter range, specify the design constraints, and analyze the results of each parameter variation. For this study, as evidence, the application of non-parametric statistics is adopted (Hatch \& Lazaraton, 1991).

Prior to the statistical analysis of the relationship between the predictor variables $(\mathrm{X} 1-\mathrm{X} 5)$ and the dependent variable $(\mathrm{Y})$, the results of the criterion variable (Y), viz., the students' English test are shown in Figure 2.

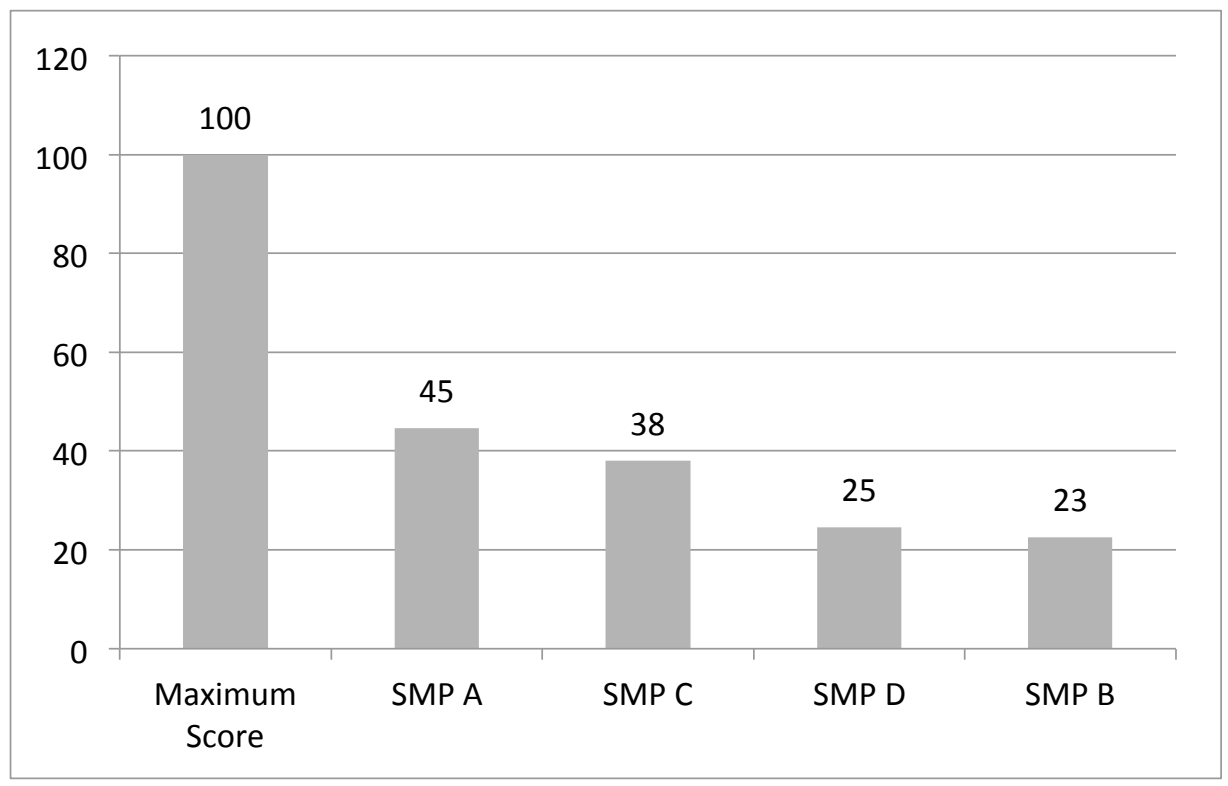

Figure 2. The Students' Summative English Achievement 
Rachmajanti \& Anugerahwati, Predictors of the Students' English Achievement 79

Figure 2 shows that the students of lower secondary schools, namely SMP A, acquired the highest score, 45, SMP C scored 38, SMP D got 25 and the lowest was SMP B, got 23.

Afterwards, the five predictor variables obtained from the students' questionnaire on the English instruction at the primary school were sorted and tallied. Tables 1, 2, 3 and 4 demonstrate the results of the statistical analysis of the relationship between the predictor variables (X1-X5) and the criterion variable (Y) using the analysis of multiple regression. The detailed descriptions, the results of the statistical analyses of multiple regression are displayed in Table 1.

Table 1. Summary of the Results of the Regression Analysis

\begin{tabular}{|c|c|c|c|c|c|c|c|}
\hline & & & Score & Interest & $\begin{array}{l}\text { Motiva } \\
\text { tion }\end{array}$ & Facilities & $\begin{array}{c}\text { Interact } \\
\text { ional } \\
\text { Process }\end{array}$ \\
\hline \multirow{10}{*}{$\begin{array}{l}\text { Spear } \\
\text { man's } \\
\text { rho }\end{array}$} & \multirow[t]{2}{*}{ Score } & $\begin{array}{l}\text { Correlation } \\
\text { Coefficient }\end{array}$ & 1.000 & $.501^{* * *}$ & .198 & $.473^{* *}$ & $.307^{*}$ \\
\hline & & Sig. (2-tailed) & - & .000 & .120 & .000 & .014 \\
\hline & \multirow[t]{2}{*}{ Interest } & $\begin{array}{l}\text { Correlation } \\
\text { Coefficient }\end{array}$ & $.501^{* *}$ & 1.000 & $.481^{* *}$ & $.780^{* *}$ & $.576^{* *}$ \\
\hline & & Sig. (2-tailed) & .000 & . & .000 & .000 & .000 \\
\hline & \multirow[t]{2}{*}{ Facilities } & $\begin{array}{l}\text { Correlation } \\
\text { Coefficient }\end{array}$ & $.473^{* *}$ & $.780^{* *}$ & $.388^{* *}$ & 1.000 & $.399^{* *}$ \\
\hline & & Sig. (2-tailed) & .000 & .000 & .002 & . & .001 \\
\hline & \multirow{2}{*}{$\begin{array}{l}\text { Interactional } \\
\text { Process }\end{array}$} & $\begin{array}{l}\text { Correlation } \\
\text { Coefficient } \\
\end{array}$ & $.307^{*}$ & $.576^{* *}$ & $.501^{* *}$ & $.399^{* *}$ & 1.000 \\
\hline & & Sig. (2-tailed) & .014 & .000 & .000 & .001 & . \\
\hline & \multirow[t]{2}{*}{ Motivation } & $\begin{array}{l}\text { Correlation } \\
\text { Coefficient } \\
\end{array}$ & .198 & $.481^{* *}$ & 1.000 & $.388^{* *}$ & $.501^{* *}$ \\
\hline & & Sig. (2-tailed) & .120 & .000 & . & .002 & .000 \\
\hline Notes: & & & & & & & \\
\hline
\end{tabular}


As seen in Table 1 we discovered that the combinations of the independent variables and the dependent variable were significantly correlated (F Sig. < .05). Therefore, there revealed a model of relation, namely, the combination of the predictor variables 1 up to 5 (interest, motivation, facilities and interactional process) and the criterion variable (students' English achievement). The following is the result of analysis for the hypothesis testing (see Table 2).

Table 2. The Result of the Statistical Analysis of Multiple Regression

\begin{tabular}{lrrrrr}
\hline Model & $\begin{array}{c}\text { Sum of } \\
\text { Squares }\end{array}$ & df & Mean Square & F & Sig. \\
\hline Regression & 3423.091 & 4 & 855.773 & 4.459 & $.003^{\text {b }}$ \\
Residual & 11130.387 & 58 & 191.903 & & \\
\hline Total & 14553.478 & 62 & & & \\
\hline
\end{tabular}

Notes: a. Dependent Variable: Score

b. Predictors: (Constant), Motivation, Facilities, Exposure in Interactional Process, Interest.

Table 2 shows that the value of Sig. F was $0.003(p<0.05)$, meaning that the alternative hypothesis stating that there is some positive and significant contribution of the independent variables in combination to the students' learning achievement in English at the lower secondary school in CLIL context was not rejected. In other words, each of the predictor variables: motivation (both internal and external), the provision of facilities (such as references in English, videos in English), students' interest, and the amount of exposure (the use of English as a medium of instruction) in the interactional process altogether provided significant contribution to English achievement in their lower secondary school. However, the value of contribution of each of the selected predictor variables: interest, motivation, facilities and interactional process on the criterion variable: the students' English achievement, is not the same, as demonstrated in Table 3.

Based on the summary in Table 3, it was revealed that the variables of interest, motivation, facilities and interactional process contribute $34 \%,-26 \%$, $19.6 \%,-23.5 \%$, respectively to the students' English achievement at secondary school level of education. This implies that the predictor variables of students'interest and the provison of facilities contribute more to their English achievement; whereas, motivation and interactional process contribute less. 
Rachmajanti \& Anugerahwati, Predictors of the Students' English Achievement 81

Table 3. The Values of Contribution of Predictor Variables

\begin{tabular}{|c|c|c|c|c|c|c|c|}
\hline \multirow{2}{*}{ Model } & \multicolumn{2}{|c|}{$\begin{array}{c}\text { Unstandardized } \\
\text { Coefficients }\end{array}$} & \multirow{2}{*}{$\begin{array}{c}\text { Standardized } \\
\text { Coefficients } \\
\text { Beta }\end{array}$} & \multirow{2}{*}{$\mathrm{t}$} & \multirow{2}{*}{ Sig. } & \multicolumn{2}{|c|}{$\begin{array}{c}\text { Collinearity } \\
\text { Statistics }\end{array}$} \\
\hline & B & $\begin{array}{l}\text { Std. } \\
\text { Error }\end{array}$ & & & & Tolerance & VIF \\
\hline (Constant) & 10.627 & 7.719 & & 1.377 & .174 & & \\
\hline Facilities & .699 & .663 & .196 & 1.053 & .297 & .380 & 2.634 \\
\hline Interest & .632 & .381 & .340 & 1.660 & .102 & .314 & 3.188 \\
\hline Interaction & -.050 & .327 & -.023 & -.154 & .878 & .595 & 1.681 \\
\hline Motivation & -.095 & .509 & -.026 & -.187 & .852 & .665 & 1.503 \\
\hline
\end{tabular}

Following are the results obtained from the analysis of the observations and interviews with the ICP teachers during monitoring sessions. In general, there is a common trend among the English teachers in the observed schools. Firstly, the teachers have used English most of the time, although with different intensity (the teachers in SMP A and SMP B used English all the time, while the teachers in the other two schools used it most of the time). Secondly, all teachers have also developed Lesson Plans, albeit in different styles. The lesson plans contain the essential elements that must be included like competences to be achieved, materials to be covered, ways how to teach and ways to assess. However, not all teachers developed worksheets as one of the requirements for a complete Lesson Plan. Thirdly, in terms of classroom activities, there are varieties among the teachers in the four schools. SMP A and SMP C have conducted good interactional activities, where the students used English among themselves, not only with the teachers, whereas in other schools (SMP D and SMP B), it was observed that the class activities were still teacher-centered, where the teacher used most of the talking time, and the students just listened to them and did what the teacher instructed. Group work was also not done in all classes. One of them conducted individual work most of the time while other teachers conducted pair and small group work.

Upon the data analysis as described above, the research findings are then interpreted as follows. It was found that the contribution of the combination of two aspects of the English instruction at primary school, namely, 'students' interest' (34\%) and 'provision of facilities' $(23.5 \%)$ has an impact on the students' achievement of English at the secondary school. In other words, the students' interest and the availability of facilities (available both at school and 
home) they had at the primary school have contributed to their English achievement when they are in the secondary school. This is in line with what Ivone (1995) discovered that the students who learned English in the private courses during their elementary school age had the best English achievement when they were at the secondary school. It was inferred that the teaching of English at early ages can provide a positive effect on the students' English achievements at the first year of Junior High School.

Another possible reason for the finding is that all students enrolled in the secondary schools are highly interested in studying in the ICP classes, since they themselves chose to enrol to the ICP classes. This is probably also true for the students' classes in the primary school; hence the significant relationship between the interest and their achievement in secondary school.

Another similar study conducted by Santoso (2000) supported the aforementioned claiming that preceding educational experience at the primary school had an impact on the students' English performance at the lower secondary school. He also found out that success in language learning did not depend much on the period of formal learning but more on the quality of teaching, social factors, learner characteristics, and exposure outside the school.

Further, we discovered, related to the learner characteristics, that the students of SMP A and SMP C were well selected (the minimum entrance test score was 70) at the time they attended the ICP, meaning that they had interest in having a class with English as the medium of instruction, not only for the English subject but also Math and Science. Therefore, it did not come as a surprise that the students scored the first rank for the students of SMP A. As evidence, 33\% stated they were interested in having English as the medium of instruction, whereas, the other two lower secondary schools did not have the opportunities to administer an entrance test for input selection and had insufficient experiences in conducting more engaging learning activities, as what was postulated by Dunkin and Biddle (1974), Elley and Mangubhai (1983) and Pinter (2011) that in learning a second language for young learners, some internal and external aspects have to be accounted for such as the teacher's role, students' characteristics, environment, the instructional process in the classroom, and the immediate pupil growth as well as the long-term students' effects. As discovered and pedagogically justified by Bliesener (1994), the introduction of early teaching of English in primary schools should be equipped with an open curriculum framework in that what primary schools 
have achieved in their foreign language classes is to be utilized by secondary schools.

This study has verified that the teaching of English at the primary school has at least contributed to the students' English achievement at higher level of education, particularly for the two schools with higher scores since the Englishbased instruction has been practiced according to the international standards recommended.

This study has found that the two most influential factors for students' achievement in English in the lower secondary school are students' interest and school facilities, while exposure and the teaching-learning process have little impact, and motivation has the least impact/significance. These facts might be due to several factors that is, firstly, the fact that interest and the provision of school facilities have the greatest significance for the students' achievement in lower secondary school might be seen from the two schools which have the best scores, i.e. SMP A and SMP C. Both schools employed selection tests for students' placement, and logically students who were enrolled in those schools have very high interest. Secondly, the provision of school facilities is another factor which is linked to the best schools. As we all know, primary schools mostly conduct their teaching-learning process in fun and play activities. That way, students will enjoy their time at school, and thus love learning, including learning English. Thus, being able to provide students with good facilities for their learning logically affects the students' scores, and thus making them learn better. However, facilities here do not always refer to school facilities, but also those at the students' homes. It stands to reason, then, that when the students have good facilities for "learning" English at home, their scores will be much higher.

The three other factors in the questionnaire, i.e. teaching-learning process, motivation, and exposure to English play very little significance. This might be due to the fact that in those schools, the teachers still have insufficient knowledge and skill in teaching as is expected and required by the international framework. The Centre has provided workshops and monitoring and evaluation every semester to each school, yet it might be the case that the teachers teaching the ICP classes have not really mastered the techniques and media development for the lessons. Another reason given for the teacher-centered process was that they still needed more supervision for the best method in teaching ICP classes using the international framework and recommended techniques. 
Exposure to English is also insufficient due to lack of English references in the three subjects (English, Math, and Science), and that would somehow affect the students' achievement. According to Pavesi, Bertocchi, Hofmannova, and Kazianka (2002), to have an impact, the exposure to L2 should at least be $25 \%$ of the total teaching-learning process. Some teachers gave the excuses that they still had to use the Indonesian language because students would not get what they explained when they used English all the time; it resulted in the teachers using English only at the beginning and the end of the lessons. During the lessons they used English only occasionally. When they gave instructions in English they would often translate them into Indonesian. This, of course, caused the lack of exposure, which in turn led to the students' opinion that exposure to English did not affect their English achievement in secondary school.

Lastly, the finding that motivation contributed very little to the students' English achievement in secondary school might be surprising, but some explanation can justify it. The students generally enrolled at the (primary) school with high interest (as is shown in the finding above) to study at ICP classes which used international framework. However, as time went by, with little or insufficient exposure to English, and uninteresting process of instruction and interaction, the interest might have waned, and thus their motivation (both internal and external) would also decrease. Exposure to English should always be maintained, since, like Butler (2015) concludes, children's motivation to learn foreign language will easily decline over time. Teachers, therefore, need to sustain their motivation, and one of the ways is by exposing them to the language continuously.

\section{CONCLUSIONS}

Several conclusions can be drawn from this study. First, that in CLIL context, there are some dominant factors in the teaching of English at the primary school level linked to the students' English achievement at the lower secondary school. Second, motivation (both internal and external), the provision of facilities, students' interest, the amount of exposure, and the interactional process in the primary school altogether significantly contribute to students' English learning achievement in their lower secondary school. Third, the variables of facilities, interest, interactional process, and motivation 
contribute $19.6 \%, 34 \%,-23 \%$, and $-26 \%$ respectively to the students' English achievement at secondary school level of education.

In general, out of the variables investigated, the variables of facilities and interest at the primary school are more closely linked to the students' English achievement at lower secondary school level of education. Several reasons can possibly account for this finding. The varied conditions in the primary school level, such as the learning environment, can encourage primary school students to take interest in the English lessons. The provision of facilities, moreover, can further make students love English in their primary school, which in turn, will carry on to their achievement in secondary school.

The other factors, as a matter of fact, give less contribution to the students' achievement. The finding that exposure to the language plays a minor role can understandably be accepted as, firstly, many teachers during the instructional process do not really expose their students to English, not in listening to and understanding the speech of native speakers; secondly, many times they do not even listen and respond to the teachers' speech as they speak mainly in Indonesian. Instructional processes are of the same case. Not all teachers of English in primary schools have the competence of conducting studentcentered instruction as what is required in this era. They mostly still conduct teacher-centered instructions where the activities and interactions are mostly one-way, from teacher to students. In that case, students do not feel any contributions of the instructional process to their achievements in secondary school.

The fact that motivation contributes the least to the students' achievement might be caused by the combination of the other factors. Students probably enter the primary schools, especially if the school has an ICP class, with high motivation and hopes. As time goes by, however, with the lack of exposure and uninteresting interactional/instructional process, their motivation might wane.

Based on these findings, several recommendations are offered to the secondary school stakeholders, to the teachers, to centres of Cambridge Assessment and International Education, and to future researchers. The first recommendation in this study is addressed to the stakeholders of the secondary schools; they have to examine the benefits and barriers of implementing CLIL program for the sake of students' future life. Secondly, the secondary school teachers should always evaluate the whole system of conducting CLIL-based instruction, and are empowered to do some improvements. 
The third recommendation is addressed to the Centre of Cambridge Assessment and International Education (CAIE) of Universitas Negeri Malang in order to investigate the effectiveness of the program as the main duty is to scaffold and improve the quality of teachers (English, Math and Science). By learning from the findings of this study, the management of the CAIE can plan and develop better programs for supervising and improving their services to partner schools, so the students will get better instruction and obtain better scores in their CAIE exams.

Finally, for future researchers of EFL, the results of this study can be used as a valuable input for the development of further research. It can be the execution of research employing path analysis to have a closer look at the kind of relational patterns among variables; or a similar study with considerate variables which will contribute more to the students' English achievements in higher level of education.

\section{REFERENCES}

Bliesener, U. (1994). Foreign language teaching in Germany. Bonn: Bildung $\&$ Wissencshaft.

Butler, Y. G. (2015). Parental factors in children's motivation for learning English: A case in China. Research Papers in Education, 30(2), 164-191.

Coyle, D, Hood, P, \& Marsh, D. (2010). Content Language Integrated Learning (CLIL). New York: Cambridge University Press.

Dunkin, M. J., \& Biddle, B. J. (1974). The study of teaching. New York: Holt, Rinehart, and Winston Inc.

Elley, W. B., \& Mangubhai, F. (1983). The impact of reading on second language learning. Reading Quarterly, 19(1), 54-56.

Fontecha, A. F. (2010). Gender and motivation in EFL vocabulary production. In R. M. Jiménez (Ed.) Gender perspectives on vocabulary in foreign languages (pp. 93116). Basingtoke: Palgrave Macmillan.

Hatch, E., \& Lazaraton, A. (1991). The research manual: Design and statistics for applied linguistics. Boston: Heinle and Heinle Publishers.

Hoekstra, R., Kiers, H. A. L, \& Johnsons, A. (2012). Are assumptions of wellknown statistical techniques checked, and why (not)? Frontier Psychology, 3, 137.

Ivone, F. M. (1995). The effect of learning english in the elementary school age on the students' achievement in english as a school subject at the first year 
Rachmajanti \& Anugerahwati, Predictors of the Students' English Achievement 87

of SMPK Cor Jesu Malang. (Unpublished thesis, IKIP Malang, Indonesia).

Lasagabaster, D., \& Sierra, J. M. (2010). 'Immersion and CLIL in English: More differences than similarities', ELT Journal, 64(4), 367-375.

Pavesi, M., Bertocchi, D., Hofmannova, M., \& Kazianka, M. (2002). Teaching through a foreign language. Retrieved from http://www.ub.edu/filoan/ CLIL/teachers.pdf

Pinter, A. (2011). Children learning second languages. New York: Palgrave Macmillan.

Price, P. C., Jhangiani, R. S., \& Chiang, I. C. A. (2015). Research methods in psychology $\left(2^{\text {nd }} \quad\right.$ Canadian edition $)$ Retrieved from http://www.saylor.org/site/textbooks/

Rachmajanti, S., \& McClure, M. W. (2011). University-affiliated lab schools: A collaborative partnership between the University of Pittsburgh's Falk School and the State University of Malang Lab schools. Excellence in Higher Education, 2(1), 11-20.

Rachmajanti, S., \&Anugerahwati, M. (2014). How Universitas Negeri Malang Primary Laboratory School Prepares the Young Generation for AFTA and MDGs. Conference Proceedings, pp. 639-646, Serawak, Malaysia.

Rachmajanti, S., Zen, E. L., \& Apriana, A. (2017). Mapping the framework of immersion program at the Laboratory primary school of Universitas Negeri Malang Indonesia, The New English Teacher, 11(2)19-39.

Santoso, S. (2000). Buku latihan SPSS statistik parametrik. Jakarta: PT Elex Media Komputindo.

Tabachnick, B. G., \& Fidell, L. S. (2001). Using multivariate statistics (4 ${ }^{\text {th }}$ ed.). Boston: Allyn and Bacon. 